Ewa Kubiak*

\title{
APU, KAUSACHUN Y TAWANTINSUYO. QUECHUISMOS EN LOS NOMBRES PROPIOS DE LOS MOVIMIENTOS POLÍTICOS REGIONALES. EN EL MARGEN DE LOS ESTUDIOS SOBRE EL PAISAJE LINGÜÍSTICO CUSQUEÑO
}

\begin{abstract}
Resumen. El artículo trata de los quechuismos que aparecen en los nombres propios de los movimientos políticos de la región cusqueña. Nos interesan las voces que se puede encontrar en los carteles políticos e inscripciones presentes en el espacio público de la ciudad y su región cercana. Este estudio lo desarrollamos dentro de una investigación dedicada al paisaje lingüístico del Cusco. Tratamos de mostrar que las palabras de origen quechua sirven para subrayar la identidad indígena tanto de los mismos miembros de los partidos políticos como de su pensamiento ideológico. Acercamos también la historia de cada una de las voces y mostramos su presencia en las fuentes lexicográficas.
\end{abstract}

Palabras clave: quechuismos, Cusco, nombres propios, paisaje lingüístico.

\section{Introducción}

Las lenguas indígenas siguen vivas en las regiones andinas del Perú, especialmente en las zonas que hasta hoy en día están habitadas por las tradicionales comunidades indígenas. El idioma más hablado allí es el quechua. Aunque el $\mathrm{Cusco}^{1}$ es una ciudad bastante grande, con más de 400 mil de habitantes, es también una ciudad con fuertes tradiciones indígenas. Este último factor decide que el Cusco sea un lugar adecuado para seguir las investigaciones sobre el paisaje lingüístico y la presencia de

* Uniwersytet Łódzki.

${ }^{1}$ La forma del nombre de la ciudad «Cusco» la usamos en el artículo según la intención de sus habitantes, aunque la mayoría de los lingüistas prefiere la forma tradicional, «Cuzco» (con " $z$ "), que aparecía en los documentos españoles durante la época colonial (por ejemplo: Cerrón-Palomino, 1997: 165-170; 2006: 143-155; Carrión Ordoñez, 1993: 267-270). Pero en 1971 las autoridades de la ciudad decidieron adoptar una nueva ortografía del nombre (Cusco). 
lenguas indígenas en las inscripciones en el espacio público. Por supuesto, en las inscripciones que aparecen en el Cusco dominan los idiomas occidentales: la lengua española (por ser el idioma oficial) y el inglés (por las funciones turísticas de la ciudad).

Este artículo se sitúa dentro del campo de los estudios dedicados al paisaje lingüístico cusqueño. Las primeras investigaciones fueron posibles gracias a la participación en el seminario del profesor Wiaczesław Nowikow durante los años 2014-2016 y la preparación de la tesis de licenciatura titulada Quechuismos en las inscripciones en el espacio público de Cusco y su región cercan $a^{2}$. Los materiales iconográficos usados en el artículo los conseguimos durante sucesivas estancias en el Cusco en los años 2015, 2017 y 2018 y están relacionados con las elecciones regionales del Cusco de 2014 y 2018.

\section{Ciclos de cambios en el paisaje lingüístico}

El término «paisaje lingüístico» se refiere al concepto definido por Landry y Bourhis (1997: 25). Según estos autores, el paisaje lingüístico lo forman todas las inscripciones que se pueden notar en el espacio público. Además, está constituido por «señales, pancartas, vallas publicitarios, pósteres, letreros luminosos, escaparates, carteles y rótulos institucionales o privados visibles en el espacio público» (Franco Rodríguez, 2007: 2; Rámila Díaz, 2015: 91).

El paisaje lingüístico de cada ciudad cambia anualmente. Parecen menos importantes los cambios de las estaciones del año, contrariamente al paisaje tradicional. Sin embargo, son significantes los cambios relacionados con la vida de cada sociedad. Así pues, podemos destacar diferentes fiestas que se repiten durante el año. Para las investigaciones del paisaje lingüístico son importantes tanto las fiestas de carácter internacional (p. ej.: Semana Santa, Corpus Cristi, Navidad) y nacional (el día de Independencia) como las fiestas regionales de carácter local (Qoyllur Rit'i $i^{3}$ o Inti Raymi $i^{4}$. Otros ciclos que parecen interesantes

${ }^{2}$ Actualmente están en marcha las investigaciones con vistas a preparar una tesis doctoral, bajo la dirección del profesor Antonio María López González.

${ }^{3}$ Fiesta religiosa y peregrinaje al santuario del Señor de Qoyllurit'i. La voz Qoylluriti está compuesta de dos palabras quechuas qóyllur «estrella, lucero, astro, planeta, cuerpo celeste luminoso» y rít'i «nieve, agua de lluvia helada que baja del cielo en forma de copos blancos y ligeros. Blancura extremada o subida» (Lira y Mejía Huamán, 2008: 390 y 423).

${ }^{4}$ Inti Raymi fue la fiesta dedicada al sol y una de las más importantes durante la época incaica. Actualmente podemos observar la renovación de este ritual, pero es un 
para las investigaciones del paisaje lingüístico (especialmente sobre las inscripciones del carácter político) son los ciclos electorales. En el caso del Cusco (y de cada ciudad del Perú) podemos diferenciar dos ciclos electorales diferentes. El primer periodo dura cinco años y está relacionado con las elecciones presidenciales y las elecciones al Congreso de la República del Perú. El segundo ciclo electoral dura cuatro años y está relacionado con las elecciones regionales. La regulación de este segundo periodo, que aquí nos interesa, lo confirma la Ley Orgánica de Gobiernos Regionales del 18 de noviembre de 2002 (Ley núm. 27867).

El Consejo Regional es un órgano normativo y fiscalizador del Gobierno Regional. Está integrado por:

- el Presidente Regional,

- el Vicepresidente Regional,

- los consejeros de las provincias de cada región, con un mínimo de 7 y un máximo de 25 , los mismos que son elegidos por sufragio directo por un periodo de 4 años.

Durante nuestro trabajo de campo tuvo lugar el segundo ciclo electoral, que podemos localizar respectivamente (usando las comparaciones con las estaciones del año) en otoño (2015), invierno (2017) y la primavera (2018). Los carteles relacionados con las elecciones del año 2014 ya había desaparecido del espacio público, sin embargo, todavía fue posible encontrar una muestra de ellos. Las informaciones seguían presentes, aunque no en el centro de la ciudad, sino en los centros poblados de la región. Particularmente, los documentamos fotográficamente en Andahuaylillas y Chinchero. Y en el año 2018 aparecieron también los carteles de los sufragios de 2018, con imágenes procedentes del Cusco y Maras.

evento festivo más lúdico y turístico que religioso. La voz raymi significa 'fiesta religiosa' (Hornberger y Hornberger, 1978: 216). La palabra inti tiene su entrada en DRAE, donde encontramos la información de que la voz viene «del quechua Inti, el Sol, dios de los incas» y su significado principal es «Unidad monetaria del Perú entre 1985 y 1990». 


\begin{tabular}{|c|c|c|}
\hline $\begin{array}{r}\text { GOBERNADOR Y V } \\
\text { GOBERNADOR REGIC }\end{array}$ & CONSEJERO REGIO & \\
\hline MARQUE CON UNA CRUZ + O UN ASPAX & \multicolumn{2}{|c|}{ MARQUE CON UNA CRUZ + O UN ASPAX } \\
\hline $\begin{array}{l}\text { MOVIMIENTO ETNOCACERISTA } \\
\text { REGIONAL DE CUSCO }\end{array}$ & $\begin{array}{l}\text { MOVIMIENTO ETNOCACERISTA } \\
\text { REGIONAL DE CUSCO }\end{array}$ & \\
\hline AUTOGOBIERNO AYLLU & AUTOGOBIERNO AYLLU & \\
\hline $\begin{array}{l}\text { ACUERDO POPULAR UNIFICADO } \\
\text { (APU }\end{array}$ & $\begin{array}{l}\text { ACUERDO POPULAR UNIFICADO } \\
\text { (APU }\end{array}$ & \\
\hline $\begin{array}{l}\text { MOVIMIENTO REGIONAL } \\
\text { TAHUANTINSUYO }\end{array}$ & $\begin{array}{l}\text { MOVIMIENTO REC } \\
\text { TAHUANTINSU } \%\end{array}$ & \\
\hline $\begin{array}{l}\text { MOVIMIENTO INKA } \\
\text { PACHAKUTEQ. }\end{array}$ & $\begin{array}{l}\text { MOVIMIENT' IT' } \\
\text { PACHAKY }\end{array}$ & \\
\hline $\begin{array}{l}\text { FRENTE AMPLIO POR LA } \\
\text { JUSTICIA, VIDA Y LIBERTAD }\end{array}$ & $\begin{array}{l}\text { FRENTK APLLO POR LA } \\
\text { JUS , I, VIDA Y LIBERTAD }\end{array}$ & \\
\hline ALIANZA POR EL PROGRESO & ALIAN $\angle A$ POR EL PROGRESO & \\
\hline $\begin{array}{l}\text { PARTIDO POPULAR CRISTIANO } \\
\text { (PPC) }\end{array}$ & $\begin{array}{l}\text {.RTIDO POPULAR CRISTIANO } \\
\text { (PPC) }\end{array}$ & \\
\hline $\begin{array}{l}\text { FRENTE POPULAR AGRICOLA } \\
\text { FIA DEL PERÚ (FREPAP) }\end{array}$ & $\begin{array}{l}\text { FRENTE POPULAR AGRICOLA } \\
\text { FIA DEL PERU (FREPAP) }\end{array}$ & \\
\hline UNIÓN POR EL PERÚ & UNIÓN POR EL PERÚ & \\
\hline $\begin{array}{l}\text { PARTIDO DEMOCRÁTICO } \\
\text { SOMOS PERÚ }\end{array}$ & $\begin{array}{l}\text { PARTIDO DEMOCRATICO } \\
\text { SOMOS PERÚ }\end{array}$ & \\
\hline FUERZA POPULAR & FUERZA POPULAR & \\
\hline PERÚ NACIÓN & PERÚ NACIÓN & \\
\hline RESTAURACIÓN NACIONAL & RESTAURACIÓN NACIONAL & \\
\hline DEMOCRACIA DIRECTA & & \\
\hline 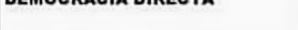 & DEMOCRACIA DIRECTA & \\
\hline ACCIÓN POPULAR & ACCIÓN POPULAR & \\
\hline
\end{tabular}

Fig. 1. Ejemplo de una cedula de sufragio para las elecciones regionales (2018)

Fuente: Diario Correo (2018).

En esta parte merece la pena mencionar que en el caso de las elecciones un proceso clave de las campañas es llegar con las informaciones a cada persona que puede votar. En este momento podemos notar que las inscripciones que aparecieron en los carteles tienen el mismo valor que los símbolos relacionados con cada partido. En la instrucción de «Cedula de sufragio para las elecciones regionales» se halla descrito el proceso de elección individual y las cartas de elecciones. Cada autogobierno regional está representado por la foto del líder, el nombre de la organización y finalmente el símbolo que hay que marcar con " $x$ " si queremos votar por este candidato. Se puede notar que en la propaganda electoral como la cartelería y en las papeletas electorales las organizaciones políticas se identifican con símbolos porque hay un grupo significativo de gente que no sabe leer. De este modo, 
la participación individual en las elecciones es posible solamente gracias a los símbolos visuales. En los carteles políticos de los autogobiernos regionales siempre aparecen los emblemas de las organizaciones políticas con las casillas de voto siempre marcadas con " $x$ " (fig. 1 ).

En el espacio público del Cusco y su región cercana encontramos los carteles con quechuismos en los nombres propios de los siguientes movimientos regionales políticos (marcados a través de la palabras escritas o las voces simbolizadas por las imágenes-emblemas): el Movimiento Regional Kausachun Cusco, Apu (el Movimiento Regional Acuerdo Popular Unificado), el Movimiento Regional Autogobiemo Ayllu, el Movimiento Regional lnka Pachacutec, el Movimiento Regional Tawantinsuyo y Papá (el Movimiento Regional Patria Arriba Perú Adelante). En este artículo para el análisis lingüístico detallado elegimos solamente las voces de origen quechua que componen los nombres propios de los movimientos regionales, que aparecieron en la forma escrita en el espacio público y no tienen sus entradas en el Diccionario de Real Academia Española. Estas son: apu, kausachun y Tawantinsuyo (figs. 2-4).

\section{Análisis de las voces del origen quechua}

\subsection{Apu. El Movimiento Regional Acuerdo Popular Unificado (APU) (fig. 2)}

En el quechua la palabra apu significa 'señor'. La definición está anotada en el diccionario bilingüe quechua-español que ofrece dos definiciones: «espíritu tutelar de un pueblo que habita en las cimas de los cerros, en los nevados, en la pañolería, o en una waka ${ }^{5}$ importante» y «jefe, mandatario, superior» (Diccionario, 1995: 21). La voz apu está muy enraizada en la cultura andina y aparece en muchas expresiones, pudiendo también juntarse con diferentes palabras 6 . La voz aparece por primera vez con la forma Appo en el diccionario de Santo Tomas (1560) con explicación: 'gran señor' (2013 [1560]: 293). Las entradas siguientes las ofrecen el Diccionario Anónimo de

\footnotetext{
${ }^{5}$ Waka o huaca: «templo, adoratorio inca» (Calvo Pérez, 2014: 349).

${ }^{6}$ En la lengua quechua tenemos expresiones como: Apu kamachi «disposición legal. Ley, mandato, superior» (con sinónimo: Apu simi); Apu P'unchaw «la imagen del sol en la época incaica»; Apu Qañakway es el nombre propio del «cerro elevado llamado balcón del Oriente, situado en Paucartambo (Qosqo, Perú) junto a Tres Cruces, de donde se observa la salida del sol con cambios lumínicos espectaculares» (Diccionario, 1995: 21-22).
} 
1586 - Apu 'señor grande, rico, poderoso' (Diccionario 1586) - y también el diccionario de Diego Gonçalez Holguín de 1608. En este último estudio el autor propone una lista amplia de vocabulario. Al lado de la forma Apu ('Señor grande o juez, o curaca principal'), anota también: Capay Apu ('rey'); Apи уира ('el hombre grave de autoridad'); Apu cunap apun ('el mayor de los juezes o superiores'); Apuyoc ('el que tiene superior') (Gonçalez Holguín, [1608] 1952: 30). Apus en la cultura andina son considerados como espíritus, que ayudan y protegen a la gente. Por ejemplo, los dioses tutelares del Cusco se llaman «Apu Salkantay, Apu Pachatusan, Apu Awsangati» (Diccionario, 1995: 21) En nuestra investigación la voz Apu aparece como el acrónimo de la organización política local «Movimiento Regional Acuerdo Popular Unificado», APU. La palabra apu es un ejemplo de los préstamos crudos (xenismos) sin adaptación lingüística a lengua española. La terminación con " $u$ " no es muy popular en la lengua española, pero en este caso la palabra mantuvo la forma original, aunque en muchas palabras " $u$ " fue cambiado por "o".
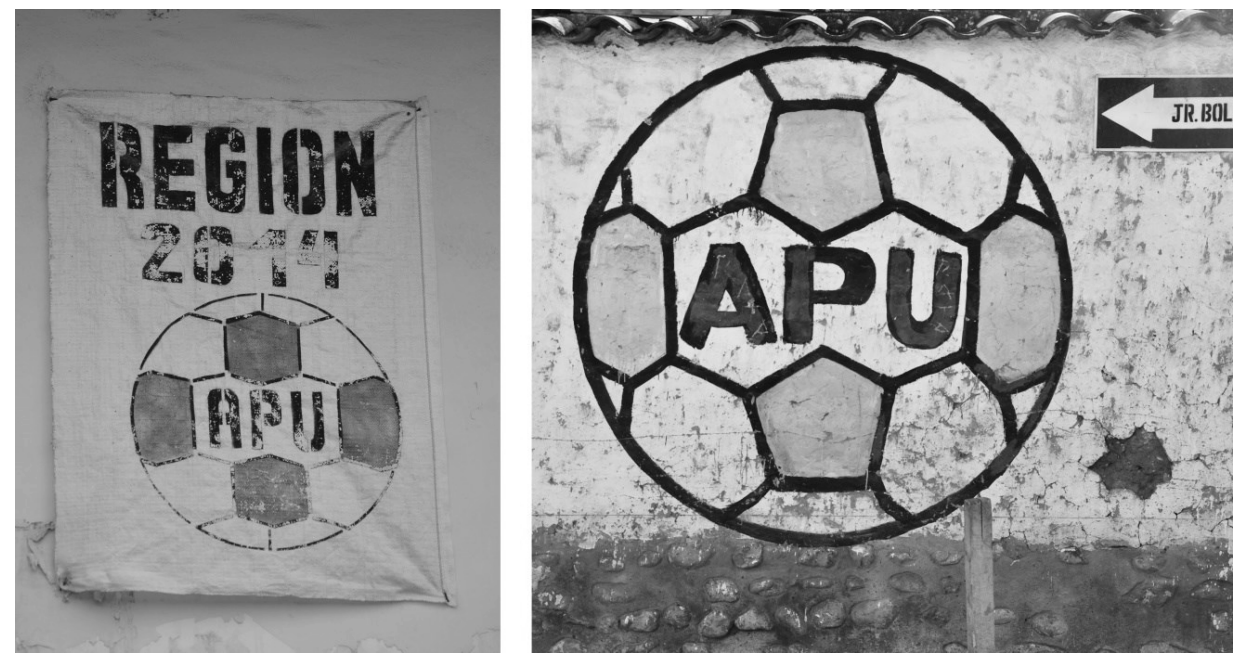

Fig. 2. Apu. El cartel político en Chinchero y la pintura mural con la publicidad del movimiento en Urubamba, después de las elecciones de 2014 (fot. Ewa Kubiak, 2017)

\subsection{Kausachun. El Movimiento Regional Kausachun Cusco (fig. 3)}

La palabra kausachun es un verbo quechua en la forma de imperativo. La forma básica del verbo es kausay (Guardia Mayorga, [1959] 1997: 107) 
o káwsay (Lira y Mejía Huamán, 2008: 180) que significa 'vivir, vive'. Por primera vez la palabra aparece en el diccionario de Santo Tomás ([1560] 2013:118) cauçani y cauçacuni con el significado 'vivir'. Después encontramos la forma más adecuada al verbo que conocemos hoy. La palabra cauçay tiene la entrada en el diccionario anónimo de 1586 con el significado 'vida' (Diccionario, 1586) ${ }^{7}$. En nuestra investigación la voz kausachun apareció en el cartel político del Movimiento Regional Kausachun Cusco en Andahuylillas y en un mural en Chichero. Los dos promovían a Edwin (EdWIN) Liconael representante del movimiento. Él se postuló a las elecciones regionales del año 2014 para la presidencia regional de Cusco. Ganó en la segunda vuelta y fue elegido presidente de la región para el periodo 2015-2018. La voz kausachun es una palabra quechua y constituye la forma verbal del imperativo. El verbo kausay adquirió el sufijo personal de imperativo -chun (Soto Ruiz, [1979] 2010: 150-151).
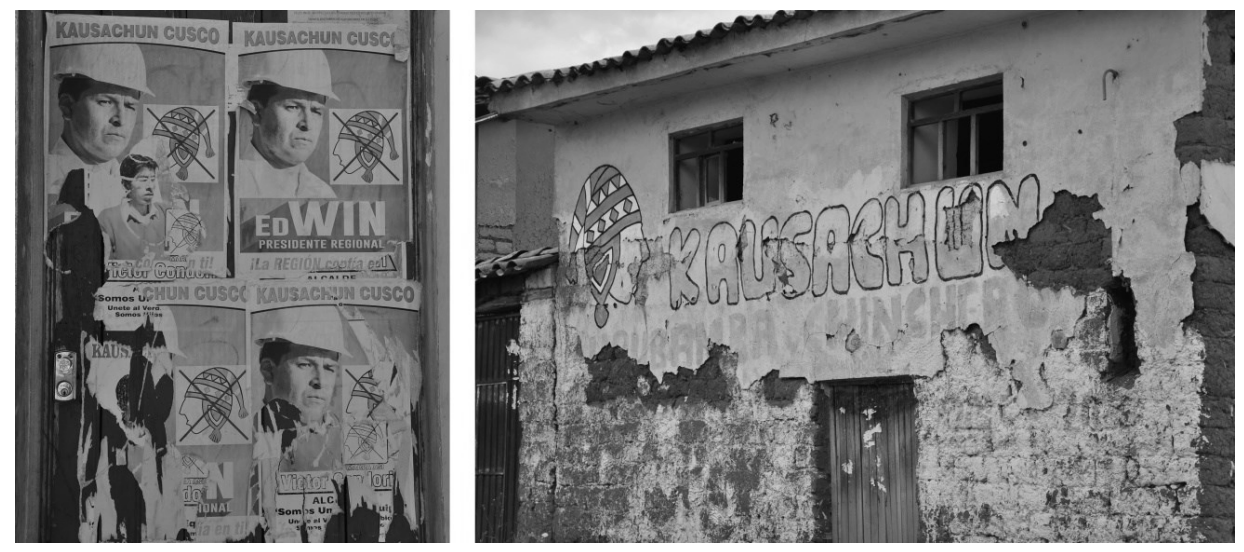

Fig. 3. Kausachun Cusco. El cartel político en Andahuaylillas y pintura mural con la publicidad del movimiento en Chinchero, después de las elecciones de 2014

(fot. Ewa Kubiak, 2015 y 2017)

\subsection{Tawantinsuyo. El Movimiento Regional Tawantinsuyo (fig. 4)}

La palabra Tawantinsuyo es una voz de origen quechua. Está compuesta de dos palabras quechuas: tawa, que significa 'cuatro' (Diccionario, 1995: 616) y suyu, que significa 'territorio' (Hornberger y Hornberger, 1978: 242)

${ }^{7}$ En el mismo diccionario se encuentra también la palabra cauçachinakuni con el significado de 'mantenerse; vivir la vida quieta los cassados' (Diccionario, 1586). 
o 'región, provincia, territorio, comarca, estado' (Diccionario, 1995: 595). Tawantinsuyo es la denominación del antiguo imperio incaico y nombra las cuatro regiones unidas. En los diccionarios aparecen las formas Tawantinsuyu (Diccionario, 1995: 617) o Tahuantinsuyu (Calvo Pérez, 2014: 649)8.
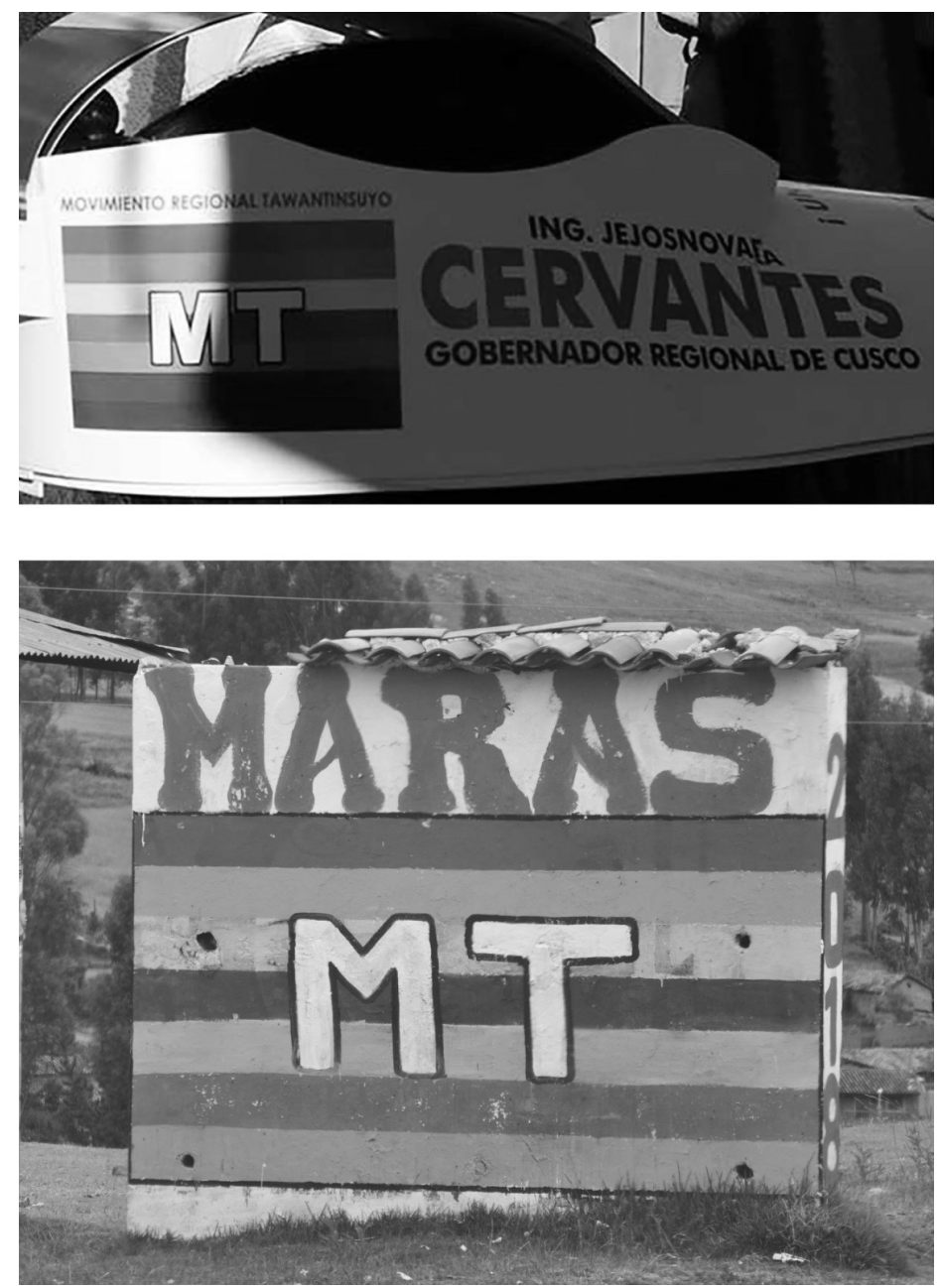

Fig. 4. Tawantinsuyo. El cartel político en Cusco y mural en el paradero Maras en el camino núm. 28G relacionados con las elecciones de 2018 (fot. Ewa Kubiak, 2017 y 2018)

${ }^{8}$ Encontramos también las voces derivadas de las palabras separadas tawa y suyu. Las expresiones derivadas de la primera voz en la mayoría son números como: tawa chunka 'cuarenta', tawa hunu 'cuatro millones', tawa pachak 'cuatrocientos' (Diccionario, 1995: 616-617). De la palabra suyu derivan por ejemplo suyuy ('ser conquistado'), suyunchay ('conquistar/incorporar terrenos a su país'), suyu unancha 'bandera territorial' (Hornberger y Hornberger, 1978: 242). 
En los diccionarios antiguos notamos tanto las palabras separadas tagua ('quatro') (Santo Tomás, [1560] 2013: 420) o tahua (Diccionario, 1586) y suyo (Santo Tomás, [1560] 2013: 411) o suyu (Diccionario, 1586), como la denominación del imperio Tahuantinsuyu con el significado:'las cuatro partes en que se divide todo el Perú, que son Antisuyu ${ }^{9}$, Collasuyu ${ }^{10}$, Cuntisuyu ${ }^{11}$,

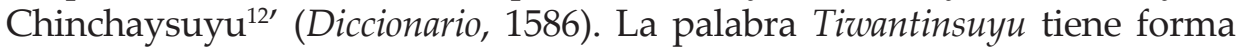
compuesta. Las dos palabras tawan y suyu se unen gracias al morfema de carácter «colectivo agrupativo -ntin», con lo que Tawantinsuyu constituye una unidad compuesta de unidades menores (Calvo Pérez, 2014: 649). En nuestra investigación la palabra aparece en la inscripción del cartel del Movimiento Regional Tawantinsuyo y lleva la forma medio españolizada. La primera parte de la palabra conserva la ortografía quechua, pero la última vocal fue cambiada; en lugar de " $\mathrm{u}$ " en la inscripción tenemos "o".

\section{Significado cultural y función de los quechuismos}

Los quechuismos en los nombres propios de los movimientos políticos los podemos tratar como la manifestación de la cultura nativa y también como una declaración política. Los líderes de los partidos saben que los cusqueños quieren fortalecer su identidad indígena, glorificar la ciudad recordando su gran historia precolombina y la presencia contemporánea de la sociedad india y mestiza. Los políticos, a través de las voces quechuas, quieren subrayar su orientación pro-indígena. Cada una de las palabras incorporadas a los nombres de los movimientos tiene una referencia directa a la cultura andina. Los quechuismos que aparecen en el espacio público de la ciudad antes de las elecciones tienen la función de atraer a los electores. Es interesante que también en los programas de los movimientos

9 Anti significa 'Este' y es la «región selvática del área andina, o región de la salida del Sol. Correspondía a Antisuyu». La palabra anti dio origen a la denominación «Andes» (Diccionario, 1995: 16-17). Antisuyu se relaciona con la región de los «Andes noreste» (Calvo Pérez, 2014: 69).

${ }^{10}$ La voz Collasuyu aparece en el diccionario anónimo de 1586 como «una de las cuatro partes deste reyno llamada asi» (Diccionario, 1586). Qolla o qulla significa 'meridional'. Calvo Pérez (2014: 252) escribe que la palabra colla: «pudiera no tener origen quechua, aunque se registra» en el diccionario de 1608. Por otro lado, la palabra Collao, que viene de colla, «parece de origen aimara» (Calvo Pérez, 2014: 253).

${ }_{11}$ Kuntisuyu es la denominación de la región occidental del imperio Tawantinsuyu, que «comprendía los actuales departamentos: Apurímac, Ayacucho, Huancavelica, Lea y parte de Arequipa» y la palabra kunti significa 'punto cardinal oeste' (Diccionario, 1995: 212).

12 Chincha significa 'Norte' (Calvo Pérez, 2014: 213). 
que podemos revisar en las páginas de internet aparezcan las expresiones quechuas, especialmente cuando se presenta los valores de los partidos políticos. Parece que el uso de la lengua quechua hace las promesas electorales parezcan de más confianza.

\section{Bibliografía}

CALVO PÉREZ, J. (2014). Diccionario Etimológico de palabras del Perú, Lima: Editorial Universitaria Universidad Ricardo Palma.

CARRIÓN ORDOÑEZ, E. (1993). «Cuzco, con z», Histórica, XVII/2, 267-270.

CERRÓN-PALOMINO, R. (1997). «Cuzco y no Cusco ni menos Qosqo», Histórica, XXI/2, 165-170.

DIARIO CORREO (2018). «La cédula. Elecciones regionales 2018. Cuzco» [en línea] <https://diariocorreo.peru.pe/lista-la-cedula-2018/cusco $>$, fecha de consulta: 28 de agosto de 2018.

Diccionario (1586). Arte y Vocabulario de la Lengva General del Perv, llamada Quichua, y en la lengua Española. El más copioso y elegante que hasta agora se ha impresso. En los Reyes [Lima], por Antonio Ricardo [facsímil].

Diccionario (1995). Diccionario Quechua-Español-Quechua/Qheswa-Español-Qheswa. Qosqo: Municipalidad de Qosqo.

DRAE (2014). Diccionario de la Real Academia Española, vigesimotercera edición [en línea] <www.rae.es>, fecha de consulta: 24 de marzo de 2015.

FRANCO RODRÍGUEZ, J. M. (2007). «El Español en el Condado de Miami Dade desde su paisaje lingüístico», Revista LinRed, 01/12, 1-29 [en línea] $<$ http://www.linred.es/articulos_pdf/LR_articulo_28112007.pdf $>$, fecha de consulta: 24 de septiembre de 2018.

GONÇALEZ HOLGUÍN, D. ([1608] 1952). Vocabulario de la lengua general de todo el Perú llamada lengua qquichua o del inca, R. PORRAS BARRENECHEA (ed.). Lima: Imprenta Santa María.

GUARDIA MAYORGA, G. ([1959] 1997). Diccionario Kechwa-Castellano. Castellano-Kechwa. Lima: Librería Editorial "Minerva".

HORNBERGER, E. y HORNBERGER, N. H. (1978). Diccionario tri-lingue: Quechua of Cusco / English / Spanish, vol. II. Quechua - Español / Inglés. Cusco: Quechua Community Ministry.

LANDRY, R. y BOURHIS, R. (1997). «Linguistic Landscape and Ethnolinguistic Vitality: An Empirical Study», Journal of Language and Social Psychology, vol. 16, 1, 23-49.

LEY núm. 27867 (2002). «Ley Orgánica de Gobiernos Regionales del 18 de noviembre de 2002» [en línea] <https://portal.jne.gob.pe/portal_documentos/ files/informacionlegal/Constitucin $\% 20 \mathrm{y} \% 20$ Leyesl/LEY\%200RGANICA $\% 20$ DE\%20GOBIERNOS\%20REGIONALES.pdf $>$, fecha de consulta: 24 de septiembre de 2018. 
LIRA, J. A. y MEJÍA HUAMÁN, M. (2008). Diccionario quechua-castellano, castellano-quechua. Lima: Editorial universitaria Universidad Ricardo Palma.

RÁMILA DÍAZ, N. (2015). «El paisaje lingüístico o la construcción de un espacio híbrido en el Instituto Cervantes de París», Estudios intralingüísticos, 3, 89-104.

SANTO TOMÁS, D. de ([1560] 2013). Lexicon, o vocabulario de la lengua general del Perv, vol. 1-2, J. CALVO PÉREZ y H. URBANO (eds.). Lima: Universidad San Martín de Porres.

SOTO RUIZ, C. ([1979] 2010). Quechua. Manual de enseñanza. Lima: Instituto de Estudios Peruanos. 